\title{
More on Diophantine Equations
}

\section{Sanjay Tahiliani}

Abstract: In this paper, we will find the solutions of many Diophantine equations.Some are of the form $2\left(3^{x}\right)+5\left(7^{y}\right)+11=z$ for non negative $x, y$ and $z$. we also investigate solutions ofthe Diophantine equation $2^{(x+3)}+11\left(3^{y}\right)-1=z^{2}$ for non negative $x, y$ and $\mathrm{z}$ and finally, westudy the Diophantine equations $(k ! \times k)^{n}=$ $(n ! \times n)^{k}$ and $\left(\frac{k !}{k}\right)^{n}=\left(\frac{n !}{n}\right)^{k}$ where $k$ and $n$ are positive integers. We show that the first one holds if and only if $k=n$ and the second one holds if and only if $k=n$ or $(k, n)=(1,2),(2,1)$. We also investigate Diophantine equation $u !+v !=u^{v}$ and $u !-v !=u^{v}$.

Key Words : Exponential Diophantine equations

\section{I.INTRODUCTION}

In 1844, Catalan [3] conjectured that $(\mathrm{a}, \mathrm{b}, \mathrm{x}, \mathrm{y})=(3,2,2,3)$ is the unique solution for the exponential Diophantine equation $\mathrm{a}^{\mathrm{x}} \square \mathrm{b}^{\mathrm{y}}=1$, (a,b, $\left.\mathrm{x}, \mathrm{y}\right) \square \mathrm{N}^{4}$ and $\min \{\mathrm{a}, \mathrm{b}, \mathrm{x}, \mathrm{y}\}>1$.

The proof of conjecture is due to Mihailescu[5] in 2004.In 2011, Suvarnamani [5] found all-non negative integer solution of the Diophantine equation $2^{\mathrm{x}}+\mathrm{p}^{\mathrm{y}}=\mathrm{z}^{2}$.

In 2012, Chotchaisthit[4] ,using this theorem, found all the solutions for the Diophantine $4^{\mathrm{x}}+\mathrm{p}^{\mathrm{y}}=\mathrm{z}^{2}$. In 2014, Yahui $\mathrm{Yu}$ and Xiaoxue $\mathrm{Li}[8]$ investigated solutions of equations of the type $2^{\mathrm{x}}+\mathrm{b}^{\mathrm{y}}=\mathrm{c}^{\mathrm{z}}, \mathrm{x}, \mathrm{y}, \mathrm{z}$ in $\mathrm{N}$, where $\mathrm{b}$ and $\mathrm{c}$ are fixed coprime positive integers with $\min (\mathrm{b}, \mathrm{c}) \square 1$.

Motivated by all these papers, In 2017, Idir Sadani[6] found the unique solution for the Diophantine equation $2^{(x+2)}+7\left(3^{y}\right)+11=z^{2}$. we tried to find the solutions of the Diophantine equations for another equations $2^{(\mathrm{x}+3)}+11\left(3^{\mathrm{y}}\right)$ $\square 1=\mathrm{z}^{2}$ and $2\left(3^{\mathrm{x}}\right)+5\left(7^{\mathrm{y}}\right)+11=\mathrm{z}^{2}$.

Also, we will establish with four new closely related Diophantine equations involving factorials.

Our work has been greatly encouraged and motivated by interesting results proved by [1] and [2]. They proved the results $\mathrm{k}^{\mathrm{n}} \times \mathrm{n} !=\mathrm{n}^{\mathrm{k}} \times \mathrm{k} !, \mathrm{k}, \mathrm{n} \in \mathrm{N}[1],(\mathrm{k} !)^{\mathrm{n}}+\mathrm{k}^{\mathrm{n}}=(\mathrm{n} !)^{\mathrm{k}}+\mathrm{n}^{\mathrm{k}}$ and $(\mathrm{k} !)^{\mathrm{n}}-\mathrm{k}^{\mathrm{n}}=(\mathrm{n} !)^{\mathrm{k}}-\mathrm{n}^{\mathrm{k}}$ [2].Here ,we study following multiplicative counterparts of (Theorem 2.1, Theorem 2.2 of [2] ) $(\mathrm{k} ! \times \mathrm{k})^{\mathrm{n}}=(\mathrm{n} ! \times \mathrm{n})^{\mathrm{k}}$ and $\left(\frac{k !}{k}\right)^{n}=\left(\frac{n !}{n}\right)^{k}$.We present all positive integer solutions $(k, n)$ of these equations. At last, we also study the properties of Diophantine equation $\mathrm{u} !+\mathrm{v}$ ! $=\mathrm{u}^{\mathrm{v}}$ and $\mathrm{u} !-\mathrm{v} !=\mathrm{u}^{\mathrm{v}}$.

\section{II.MAIN THEOREMS}

Theorem 2.1. The Diophantine equation $2\left(3^{\mathrm{x}}\right)+5\left(7^{\mathrm{y}}\right)+$ $11=\mathrm{z}^{2}$ has solution $\{(2,1,8),(3,1,10)\}$.

Manuscript received on August 31, 2020.

Revised Manuscript received on February 26, 2021.

Manuscript published on February 28, 2021.

* Correspondence Author

Dr. Sanjay Tahiliani*, Lecturer, N.K. Bagrodias, Rohini, Sec 9, New Delhi-110085.

(c) The Authors. Published by Blue Eyes Intelligence Engineering and Sciences Publication (BEIESP). This is an open access article under the CC BY-NC-ND license (http://creativecommons.org/licenses/by-nc-nd/4.0/)
Proof. Let $\mathrm{x}, \mathrm{y}$ be non negative integers and $\mathrm{z}$ be a non negative even integer such that $2\left(3^{\mathrm{x}}\right)+5\left(7^{\mathrm{y}}\right)+11=\mathrm{z}^{2}$. We need to consider several cases:

Case 1. If $y=0$, then we have $2\left(3^{x}\right)+16=z^{2}$.Now, $z$ being even, so $z=2 k$ or positive $k$. Hence $2\left(3^{X}\right)=z^{2}-16=$ $4 \mathrm{k}^{2}-16$.This gives $2\left(3^{\mathrm{x}}\right)=0(\bmod 4)$, which is a contradiction.

Case 2. Put $y=1$, then we have $2\left(3^{x}\right)+46=z^{2}$.Now, when $x=1$, there will be no such $(x, z)$ possible. When $x=2$, the solution set is $(x, z)=(2,8)$

when $x=3$, the solution set is $(x, z)=(3,10)$ as $3\left(2.3^{x-1}-1\right)$ $=(\mathrm{z}-7)(\mathrm{z}+7)$ gives $\mathrm{z}-7=3$ and so $\mathrm{z}=10$ since $2.3^{\mathrm{x}-1}-1$ is prime .Also $1 .\left(2 \cdot 3^{\mathrm{x}}-3\right)=(\mathrm{z}+7)(\mathrm{z}-7)$, hence $\mathrm{z}-7=1$ gives $\mathrm{z}=8$ and $2.3^{\mathrm{x}}-3=\mathrm{z}+7$ gives $\mathrm{x}=2$ at $\mathrm{z}=8$. Similarly when $\mathrm{x}>3,2.3^{\mathrm{x}-}$ ${ }^{1}-1$ is non prime.

Case 3. Now, we will prove that $\mathrm{y}=1$ is the unique value. We have $2\left(3^{\mathrm{x}}\right)+5\left(7^{\mathrm{y}}\right)+11=\mathrm{z}^{2}$. So $2\left(3^{\mathrm{x}}+1\right)+5\left(7^{\mathrm{y}}+1\right)=\mathrm{z}^{2}$ -4 . Now as $\mathrm{z}^{2}-4$ is even, hence $2\left(3^{\mathrm{x}}+1\right)+5\left(7^{\mathrm{y}}+1\right)=2^{\mathrm{a}} \mathrm{b}$ $+2^{\mathrm{C}} \mathrm{d}$, this gives $7^{\mathrm{y}}+1=2^{\mathrm{C}}$ which gives a unique value of $y=1$. If $y=0$, then its not possible.Hence the solution of the Diophantine equation $2\left(3^{\mathrm{x}}\right)+5\left(7^{\mathrm{y}}\right)+11=\mathrm{z}^{2}$ is $\{(2,1,8),(3,1,10)\}$

Corollary 2.1. $(2,1,2)$ is a unique non negative integral solution $(\mathrm{x}, \mathrm{y}, \mathrm{t})$ for the Diophantine equation $2\left(3^{\mathrm{X}}\right)+5\left(7^{\mathrm{y}}\right)+$ $11=t^{6}$, where $x, y$ and $z$ are non negative integers.

\section{Proof. Obvious.}

Theorem 2.2. The Diophantine equation $2^{(\mathrm{x}+3)}+11\left(3^{\mathrm{y}}\right)$ $-1=z^{2}$ has a unique solution given by $(x, y, z)=(2,1,8)$.

Proof. Let $\mathrm{x}$ and $\mathrm{y}$ be the non negative integers and $\mathrm{z}$ be an even integer such that $2^{(\mathrm{x}+3)}+11\left(3^{\mathrm{y}}\right)-1=\mathrm{z}^{2}$.

We consider several cases:

Case 1. If $y=0$, Then, $2^{(x+3)}+10=z^{2}$.If we take $z=2 k$, we obtain $2^{(\mathrm{x}+2)}+5=2 \mathrm{k}^{2}$. But $2^{(\mathrm{x}+2)}=0(\bmod 2)$, which contradicts $2^{(\mathrm{x}+2)}+5=2 \mathrm{k}^{2}$.

Case 2. If $y=1$, then, $2^{(x+3)}+2^{5}=z^{2}$. The solution of this equation is $(2,8)([7]$, Theorem2.2). Hence the solution to our equation is $(2,1,8)$.

Case 3. If $\mathrm{y}>1$, we have $2^{(\mathrm{x}+3)}$ $+11\left(3^{\mathrm{y}}\right)-1=8\left(2^{\mathrm{x}}+1\right)+11\left(3^{\mathrm{y}}+1\right)-20=\mathrm{z}^{2}$.

Now, as $z^{2}+20$ is even, so $8\left(2^{\mathrm{x}}+1\right)+11\left(3^{\mathrm{y}}+1\right)=2^{\mathrm{j}} \mathrm{c}$ $+2^{\mathrm{k}} \mathrm{d}$.Then we deduce that $\mathrm{j}=3$ and $1+3^{\mathrm{y}}=2^{\mathrm{k}}$. The unique solution for the equation $1+3^{\mathrm{y}}=2^{\mathrm{k}}$ is $(\mathrm{y}, \mathrm{k})=(1,2)$. Hence $(2,1,8)$ is the unique solution.

Published By:

Blue Eyes Intelligence Engineering $\&$ Sciences Publication

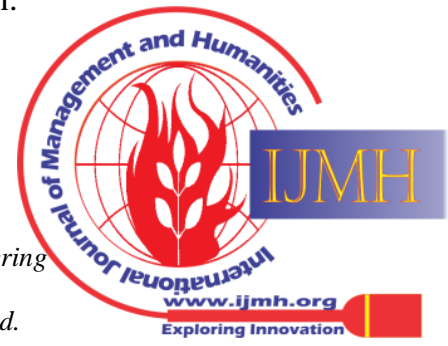




\section{More on Diophantine Equations}

Corollary 2.2. $(2,1,2)$ is the unique non negative integral solution $(\mathrm{x}, \mathrm{y}, \mathrm{t})$ for the Diophantine equation $2^{(\mathrm{x}+3)}$ $+11\left(3^{\mathrm{y}}\right)-1=t^{6}$, where $\mathrm{x}, \mathrm{y}, \mathrm{t}$ are non negative integers.

Theorem 2.3. Let $n$ and $k$ be positive integers. The equation

$(\mathrm{k} ! \times \mathrm{k})^{\mathrm{n}}=(\mathrm{n} ! \times \mathrm{n})^{\mathrm{k}}$ holds if and only if $\mathrm{n}=\mathrm{k}$.

Proof. We may show that above equation implies $k=n$. By symmetry,

We may assume that $\mathrm{n} \geq \mathrm{k}$. We consider three cases:

Case 1. $k=1$.Then $n ! \times n=1$. This gives $n=1$.

Case 2. $k=2$. Then $(n ! \times n)^{2}=4^{n}$ or $n ! \times n=2^{n}$.

Now we have $n=2^{a}$ for some $a \geq 1$. So we obtain $2^{n-a}=$ $n !$.

Now if $\mathrm{n} \geq 3$, L.H.S is not divisible by 3, but R.H.S is divisible by 3 .So $n=2$.

Case 3. $\mathrm{k} \geq 3$.From ([2], Theorem 2.2 ), we have $\mathrm{k}^{\mathrm{k}} \mid \mathrm{n}^{\mathrm{k}}$, $\mathrm{k}^{\mathrm{k}}>\mathrm{n}^{\mathrm{k}}$ and $\mathrm{n}=\mathrm{bk}$ for $\mathrm{b} \geq 1$.

Now we have $k^{\mathrm{n}}\left|\mathrm{n}^{\mathrm{k}}=(\mathrm{n} !)^{\mathrm{k}}\right|(\mathrm{k} !)^{\mathrm{n}}$.So $(\mathrm{n} !)^{\mathrm{k}}>(\mathrm{k} !)^{\mathrm{n}}$.

Hence $((b k) !)^{k}>(k !)^{b k}$. Which is false.So $b=1$ and $k=n$.

Theorem 2.4. Let $n$ and $k$ be positive integers. The equation

$\left(\frac{k !}{k}\right)^{n}=\left(\frac{n !}{n}\right)^{k}$ holds if and only if $\mathrm{k}=\mathrm{n}$ or $(\mathrm{k}, \mathrm{n})$ $=(1,2),(2,1)$.

Proof. Obviously if $k=n$ or $(k, n)=(1,2),(2,1)$, then the above equation is valid. Next we show that if above equation holds with $k<n$, then we obtain $(k, n)=(1,2)$. We distinguish three cases.

Case $1 . \mathrm{k}=1$.Then above equation reduces to $\mathrm{n} !=\mathrm{n}$, which gives $n=1,2$.

Case 2. $\mathrm{k}=2$. Same as above. Also, no solution for $\mathrm{n}>2$.

Case 3. $\mathrm{k} \geq 3$. We have $(n !)^{\mathrm{k}}>(\mathrm{k} !)^{\mathrm{n}}$ and $-\mathrm{n}^{\mathrm{k}}>-$ $\mathrm{k}^{\mathrm{n}}$.[(2), Theorem 2.1$]$.

So we have $\left(\frac{k !}{k}\right)^{n}>\left(\frac{n !}{n}\right)^{k}$. Hence proof is complete.

Theorem 2.5. For naturals $\mathrm{u}$ and $\mathrm{v}, \mathrm{u} !+\mathrm{v} !=\mathrm{u}^{\mathrm{v}}$ holds only when $(u, v)=(2,2),(2,3)$.

Proof. If $(\mathrm{u}, \mathrm{v})=(1,1)$ result will not hold. Whereas if $(\mathrm{u}, \mathrm{v})=(2,2),(2,3)$.Result holds.

We will now show that result does not hold for $u \geq 3, v \geq 3$.

If $\mathrm{u}$ and $\mathrm{v}$ are equal,then $2 \times \mathrm{u} !=\mathrm{u}^{\mathrm{u}}$, which is not possible for any $\mathrm{u} \geq 3$.

If $\mathrm{u}>\mathrm{v}>3$, then $\mathrm{u} !+\mathrm{v} !=\mathrm{u}^{\mathrm{v}}$

gives $\frac{u !}{v !}+1=\frac{u^{v}}{v !}$, so $1=\frac{u^{v}-u !}{v !}$. Now for $\mathrm{u}>\mathrm{V}>3, \frac{u^{v}-u !}{v !}<1$.

Hence we get $1<1$, not possible.

Hence, For naturals $\mathrm{u}$ and $\mathrm{v}, \mathrm{u} !+\mathrm{v} !=\mathrm{u}^{\mathrm{v}}$ holds only when $(\mathrm{u}, \mathrm{v})=(2,2),(2,3)$.

Theorem 2.6. For naturals $\mathrm{u}$ and $\mathrm{v}, \mathrm{u} !-\mathrm{v} !=\mathrm{u}^{\mathrm{v}}$ has no solution

Proof. Let $\mathrm{u} !-\mathrm{v} !=\mathrm{u}^{\mathrm{v}}$. So $1=\frac{u !-u^{v}}{v !}<1$ or $1=\frac{u !-u^{v}}{v !}>$ 1 , which is not possible for any naturals $u$ and v.Hence, for naturals $\mathrm{u}$ and $\mathrm{v}, \mathrm{u} !-\mathrm{v} !=\mathrm{u}^{\mathrm{v}}$ has no solution.

\section{CONCLUSION}

We solved many Diophantine equations . The equation $(\mathrm{k} ! \times \mathrm{k})^{\mathrm{n}}=(\mathrm{n} ! \times \mathrm{n})^{\mathrm{k}}$ has solution for $\mathrm{n}=\mathrm{k}$ where $\mathrm{n}$ and $\mathrm{k}$ are positive integers.Similarly, The equation $\left(\frac{k !}{k}\right)^{n}=\left(\frac{n !}{n}\right)^{k}$ holds if and only if $\mathrm{k}=\mathrm{n}$ or $(\mathrm{k}, \mathrm{n})=(1,2),(2,1)$ where $\mathrm{n}$ and $\mathrm{k}$ are positive integers.Also, For positive integers $u$ and $v, u$ ! $+v$ ! $=\mathrm{u}^{\mathrm{v}}$ holds only when $(\mathrm{u}, \mathrm{v})=(2,2),(2,3)$ and $\mathrm{u} !-\mathrm{v} !=\mathrm{u}^{\mathrm{v}}$ has no solution. Also the equations $2\left(3^{\mathrm{x}}\right)+5\left(7^{\mathrm{y}}\right)+11=\mathrm{z}^{2}$ has two solution $\{(2,1,8),(3,1,10)\}$ and the equation $2^{(\mathrm{x}+3)}$ $+11\left(3^{\mathrm{y}}\right)-1=\mathrm{z}^{2}$ has a unique solution given by $(\mathrm{x}, \mathrm{y}, \mathrm{z})=$ $(2,1,8)$.

\section{IV.APPLICATIONS OF DIOPHANTINE EQUATIONS}

Diophantine equations can be reduced modulo primes ad then occurs in coding theory and cryptography. For example ,elliptic curve cryptography is based on doing calculations in Galois theory for Diophantine equation of degree 3 in two variables. Morever Diophantine equations are extensively useful in algebric topology and algebraic geometry in the way of analogy existing between Diophantine equations and geometry of complex numbers. Likewise there is a deep connection of representation theory of Lie groups and number theory.

It is useful too in dynamics through small approximations and in chemistry through balancing chemical equations.

\section{REFERENCES}

1. Alzer, H, Luca, F.(2017). Diophantine equations involving factorials. Mathematica Bohemica.142 2, 181-184.

2. Carnal, H(2012). Aufgaben, Elem.Math. 67 151-154.

3. Catalan, E. (1844) Noteextraite dune lettre adressee a lediteur, $J$. Reine. Angew. Math., 27,192.

4. Chotchaisthit, $\mathrm{S}(2012)$. On the Diophantine equation $4^{\mathrm{x}}+\mathrm{p}^{\mathrm{y}}=\mathrm{z}^{2}$, wherep is a prime number, Amer.J.Math.Sci. Vol 1 191-193.

5. Mihailescu,P. (2004). Primary cyclotonic units and a proof of a catalian Conjecture, J.Reine Angew.Math. 27 167-195.

6. Sadani, I. (2017). On Diophantine equation $2^{(\mathrm{x}+2)}+7\left(3^{\mathrm{y}}\right)$ $+11=\mathrm{z}^{2}$,Tatra Mountains Mathematical Publications, 70, 217- 219.

7. Surarnamani, A. (2011). Solutions to the Diophantine equation $2^{\mathrm{X}}$ $+\mathrm{p}^{\mathrm{y}}=\mathrm{z}^{2}$, Int.J.Math.Sci.Appl $1,1415-1419$.

8. Yu, Y. and Li, X. The exponential Diophantine equation $2^{\mathrm{X}}+\mathrm{b}^{\mathrm{y}}=\mathrm{c}^{\mathrm{Z}}$ . Sci. World J., Vol.2014 ,Article ID 401816, 1-3.
Published By:

Blue Eyes Intelligence Engineering \& Sciences Publication

(C) Copyright: All rights reserved. 